\title{
ELECTROCARDIOGRAPHIC CHANGES IN HYPOTHERMIA
}

\author{
BY
}

\author{
N. A. WYNNE, J. A. FULLER, AND P. SZEKELY \\ From the Department of Physiology, King's College, University of Durham, \\ and the Cardiovascular Department, Newcastle General Hospital \\ Received January 25, 1960
}

There are already numerous reports on the electrocardiographic changes occurring in experimental and clinical hypothermia. The characteristic pattern consists of progressive bradycardia, prolongation of the P-R, QRS, and Q-T intervals, changes in the S-T segment, and occasional ventricular fibrillation (Churchill-Davidson et al., 1953; Ross, 1954; Fleming and Muir, 1957; Emslie-Smith, 1958; Emslie-Smith et al., 1959). Emslie-Smith (1958) expressed the view that this electrocardiographic pattern and especially the $J$ deflection at the junction of the QRS complex and the S-T segment is pathognomonic of the hypothermic state. In our own studies we have been particularly interested in the pharmacological behaviour of the hypothermic heart. In the present paper we propose to describe briefly the cardiographic changes we have observed in the experimental animal at various stages of cooling, and in a separate communication we intend to discuss the effects of digitalis under hypothermic conditions.

\section{MATERIAL AND Method}

Hypothermia was produced in 48 cats and 7 dogs by covering the anæsthetized animal with crushed ice. The lowest rectal temperature reached in these experiments was $17^{\circ} \mathrm{C}$. Rewarming was achieved by placing the animal on a warm radiator. In four additional experiments we studied the effect on the S-T segment of focal cooling, which was carried out by placing a test tube filled with iced water on the conus area of the exposed right ventricle. The blood pressure was measured by a mercury manometer connected to the carotid artery. Electrocardiograms, usually three limb leads and occasionally chest leads, were taken at the start of the experiment and then at very frequent intervals during cooling and rewarming.

\section{RESULTS}

The electrocardiographic changes observed in cats and dogs were similar in character and frequency, except that ventricular fibrillation was more common in dogs. A characteristic sequence of events during cooling is shown in Fig. 1 and 2.

Heart Rate and $A-V$ Conduction. In all experiments there was a progressive slowing of the ventricular rate, due at first to sinus bradycardia. The P-R interval became longer, but did not always exceed the upper limit of normal. Partial or complete A-V dissociation appeared in half of the experiments at temperatures between $19^{\circ} \mathrm{C}$. and $32^{\circ} \mathrm{C}$.

These changes were in principle reversible on rewarming. However, complete heart block behaved unpredictably: in some experiments it appeared intermittently during the cooling period (Fig. 3) and, when it was associated with a mean arterial blood pressure of less than $40 \mathrm{~mm}$. $\mathrm{Hg}$, rewarming was occasionally accompanied by a further fall in the blood pressure and persistence of a slow idioventricular rhythm, until cessation of electrical activity or the appearance of ventricular fibrillation. 
$P, Q R S$, and $T$ Waves. $\quad \mathrm{P}$ wave changes were inconsistent, showing either a decrease or increase in amplitude, and occasionally there was a complete atrial standstill. The QRS complex became wider in several experiments, but the upper limit of normal was only exceeded when idioventricular rhythm appeared. T wave changes in the form of lowering or inversion appeared in every experiment. These changes were also reversible, when the temperature was restored to normal.

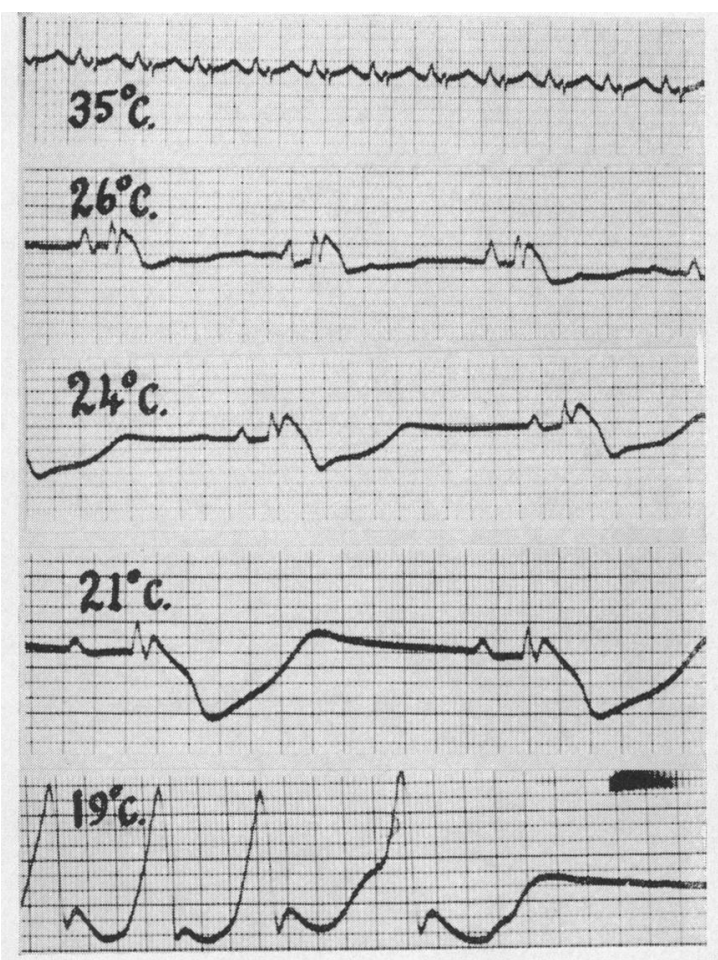

FIG. 1.-Cat, weight $2.6 \mathrm{~kg}$., lead II. Hypothermia deflection at the junction of the QRS complex and the S-T segment at $26^{\circ} \mathrm{C}$. Ventricular tachycardia followed by asystole at $19^{\circ} \mathrm{C}$.

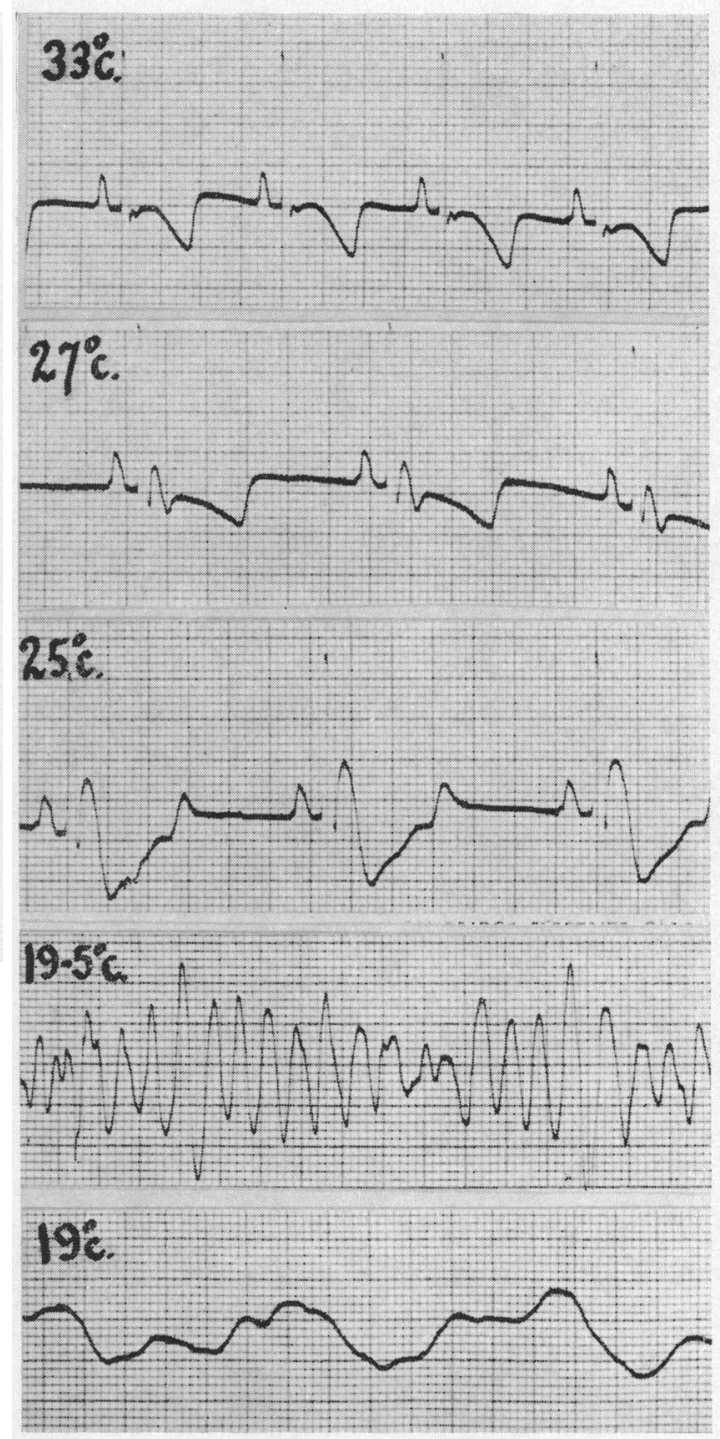

FIG. 2.-Dog, weight $8.6 \mathrm{~kg}$., lead II. Junctional deflection first observed at $27^{\circ} \mathrm{C}$. Ventricular tachycardia at $19 \cdot 5^{\circ} \mathrm{C}$. and ventricular fibrillation at $19^{\circ} \mathrm{C}$.

$S-T$ Segment. Slight elevation of the S-T segment often preceded the development of the characteristic $\mathrm{J}$ deflection, which was first seen at $28^{\circ} \mathrm{C}$. and became progressively larger as the temperature fell. This characteristic hypothermia deflection was also reversible (Fig. 4).

$Q-T$ Interval. The $\mathrm{Q}-\mathrm{Tc}$ interval became gradually longer as the temperature fell and it 


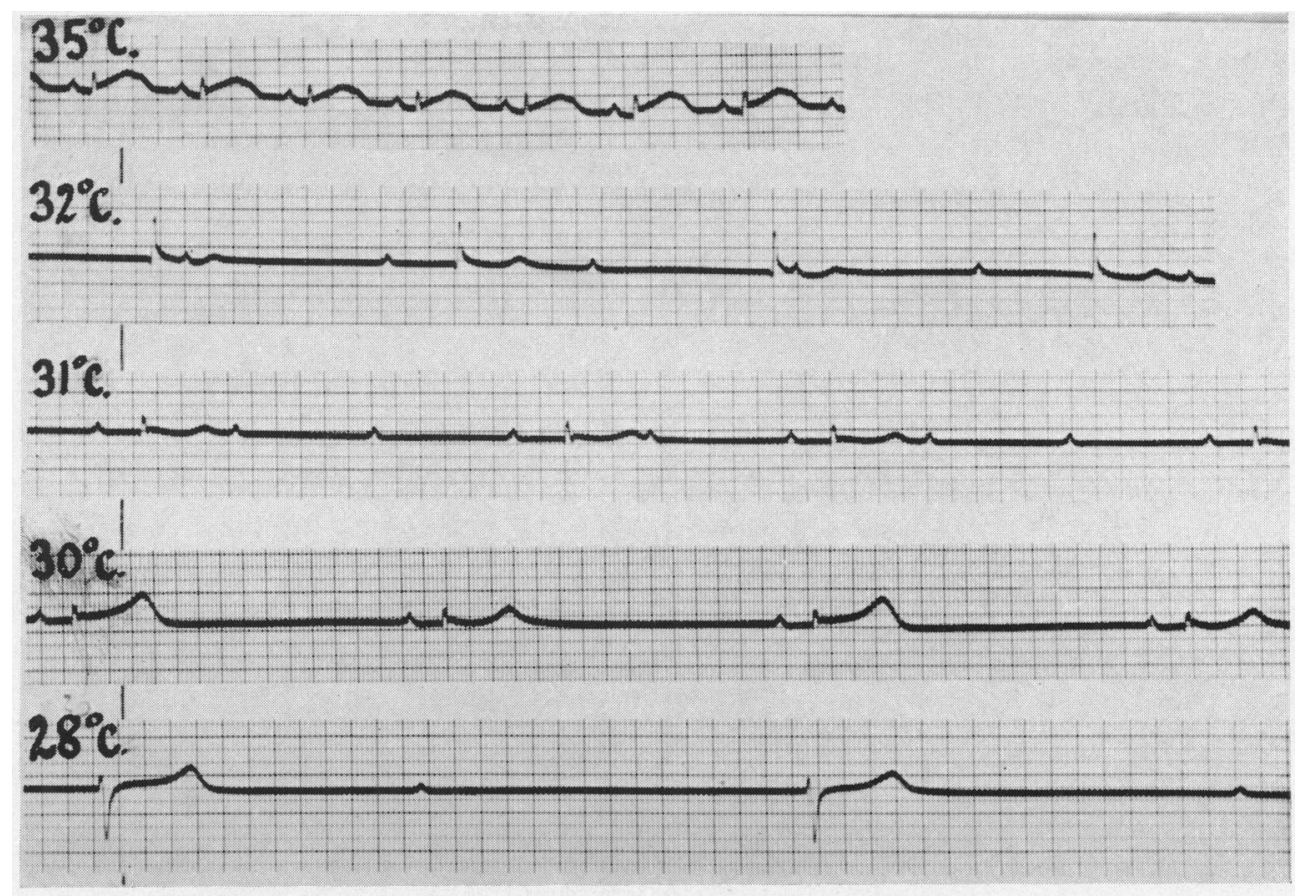

FIG. 3.-Cat, weight $2.4 \mathrm{~kg}$., lead II. Complete heart block first seen at $32^{\circ} \mathrm{C}$. Sinus rhythm at $30^{\circ} \mathrm{C}$. Re-appearance of complete heart block at $28^{\circ} \mathrm{C}$.

shortened again during rewarming. It was usually but not invariably shorter during rewarming than during cooling at comparable temperatures.

Cardiac Arrhythmias. Extrasystoles, always ventricular, were present on several occasions. Ventricular fibrillation, which was irreversible, appeared at $19.5^{\circ} \mathrm{C}$. or at a lower temperature in 17 per cent of the experiments in cats and in 50 per cent of those in dogs.

\section{DisCUSSION}

The electrocardiographic changes described in the present paper are similar to those previously observed in hypothermia in man and in the experimental animal. Emslie-Smith et al. (1959) described two basic patterns in respect of the changes in the $S-T$ segment and $T$ wave: a positive $\mathbf{J}$ deflection with inverted $\mathrm{T}$ wave, and a negative $\mathbf{J}$ deflection with upright $\mathrm{T}$ wave. The former pattern was much more common in our series.

Lange et al. (1949) thought that the electrocardiographic changes were due partly to the direct effect of cold and partly to anoxia caused by lowered oxygen dissociation. The anoxic nature of the $\mathrm{S}-\mathrm{T}$ segment and $\mathrm{T}$ wave changes seemed to them to be proved by the fact that these changes were reversed to normal by increasing the oxygen dissociation. Electrolyte changes may also play a role in the production of some of the cardiographic abnormalities, but the evidence is at present contradictory (Lange et al., 1949; Scurr, 1955; Johansson et al., 1956; Santos and Kittle, 1958; Spurr and Barlow, 1959). In this connection the findings of Angelakos et al. (1957) are of great interest : they found that dogs rendered hypercalcæmic prior to the induction of hypothermia succumbed to ventricular fibrillation at relatively high temperatures, whereas those rendered hypocalcæmic by NaEDTA infusions succumbed to asystole at much lower temperatures.

The electrocardiographic changes, except ventricular fibrillation, were reversible on rewarming 
and restoration of normal temperature. Churchill-Davidson et al. (1953) also found that ventricular fibrillation was irreversible at $22^{\circ} \mathrm{C}$. or below, but in their experience it was reversible at higher temperatures. The reversibility of the cardiographic changes suggest that they are functional in character and not due to permanent anatomical changes. However, Sarajas (1956) observed necrotic foci in the heart muscle with occasional cellular reaction in dogs subjected to moderate or to deep hypothermia of one to four hours duration. On the other hand, Johansson and Hall (1959) found no evidence of heart muscle damage.

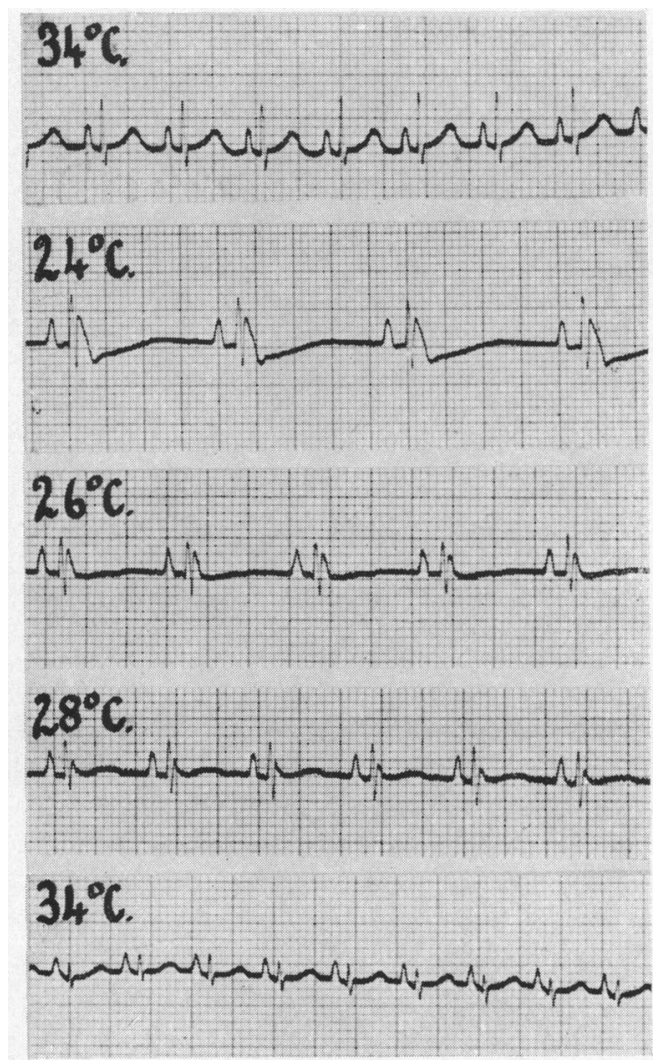

FIG. 4.-Cat, weight $1.7 \mathrm{~kg}$., lead II. Junctional deflection at $24^{\circ} \mathrm{C}$. Gradual diminution in size with complete disappearance of junctional deflection after rewarming

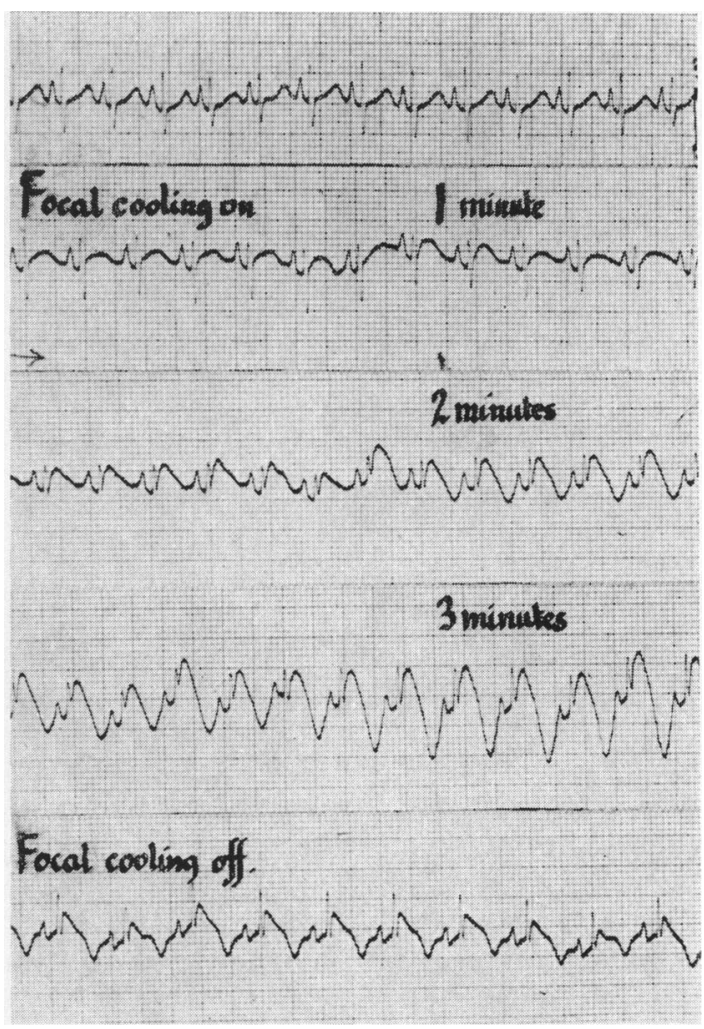

FIG. 5.-Cat, weight $2 \mathrm{~kg}$., lead II. Focal cooling. Only slight slowing of heart rate. Junctional deflection with direct transition to inverted $T$ wave.

The $\mathbf{J}$ deflection may occasionally occur after prolonged focal cooling of the right ventricle also. We were able to observe the development of this deflection on two occasions (Fig. 5); in two other instances focal cooling was followed only by elevation of the S-T segment similar to that usually seen in subepicardial injury. Following focal cooling a $\mathbf{J}$ deflection is also visible in some of the electrocardiographic complexes reproduced in Fig. 6 of the paper by Scherf et al. (1955). Furthermore, we have encountered during the past year three patients with cardiac ischæmia, whose cardiograms (Fig. 6) showed a small deflection at the junction of the QRS complex and S-T segment similar to that described by Emslie-Smith (1958) in accidental hypothermia in man. As far as we know from the routine temperatures taken in the ward these three patients were not hypothermic. These findings suggest that a focal injury may very occasionally also produce a small $\mathbf{J}$ deflection, seen constantly and to much better advantage in general hypothermia. 


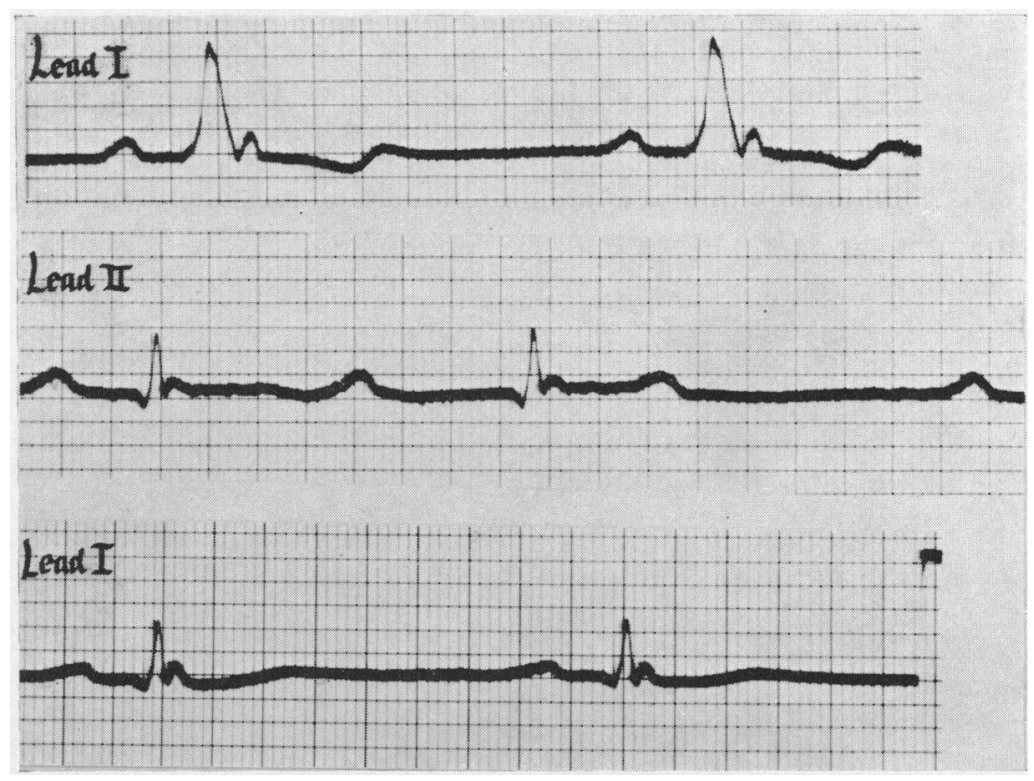

FIG. 6.-Tracings of three patients with acute cardiac ischæmia. Note small junctional deflection.

\section{SUMmaRY}

The electrocardiographic changes observed in induced hypothermia in cats and dogs are described. The most constant changes were progressive bradycardia, defective A-V conduction, prolongation of the electrical systole, and the characteristic J deflection at the junction of the QRS and S-T segment. Ventricular fibrillation occurred more frequently in dogs than in cats.

These changes, except ventricular fibrillation, proved reversible on rewarming and restoration of normal temperature.

Focal injury of the heart as produced experimentally by focal cooling of the right ventricle or by cardiac ischæmia in man can occasionally also give rise to a small $\mathbf{J}$ deflection, similar to that seen in general hypothermia.

Our thanks are due to Dr. C. B. Henderson for allowing us to reproduce one of the electrocardiograms in Fig. 6. We should also like to acknowledge a grant received by one of us (N.A.W.) from the King's College (Newcastle) Research Fund.

\section{REFERENCES}

Angelakos, E. T., Deutsch, S., and Williams, L. (1957). Circulat. Res., 5, 196.

Churchill-Davidson, H. C., McMillan, I. K. R., Melrose, D. G., and Lynn, R. B. (1953). Lancet, $2,1011$. Emslie-Smith, D. (1958). Lancet, 2, 492.

- Sladden, G. E., and Stirling, G. R. (1959). Brit. Heart J., 21, 343.

Fleming, P. R., and Muir, F. H. (1957). Brit. Heart J., 19, 59.

Johansson, B., and Hall, P. (1959). Cardiologia, 35, 171.

, Biörck, G., Haeger, K., and Sjöström, B. (1956). Acta med. Scand., 155, 257.

Lange, K., Weiner, D., and Gold, M. M. A. (1949). Ann. intern. Med., 31, 989.

Ross, D. N. (1954). Guy's Hosp. Rep., 103, 97, 116.

Santos, E. M., and Kittle, F. K. (1958). Amer. Heart J., 55, 415.

Sarajas, H. S. S. (1956). Amer. Heart J., 51, 298.

Scherf, D., Blumenfeld, S., Golbey, M., Ladopoulos, C., and Roth, F. (1955). Amer. Heart J., 49, 218.

Scurr, C. F. (1955). Proc. roy. Soc. Med., 48, 1077.

Spurr, G. B., and Barlow, G. (1959). Circulat. Res., 7, 210. 